\title{
La judicialización de la política internacional contra el terrorismo: reflexiones en torno a las sentencias Abd al Rahim al Nashiri vs. Polonia y Husayn (Abu Aubaydah) vs. Polonia ${ }^{1}$
}

The judicialization of the international policy against the terrorism: reflections about the judgments Abd al Rabim al Nashiri vs. Poland and Husayn (Al Hudaydah) vs. Poland

\section{Laura Sofía Zambrano Salazar \\ 1s.zambrano@uniandes.edu.co}

Abogada y Magíster en Derechos Humanos de la Universidad Pedagógica y Tecnológica de Colombia. Estudiante de la Maestría en Construcción de Paz de la Universidad de los Andes (Colombia). Docente de la Facultad de Derecho, Universidad Pedagógica y Tecnológica de Colombia. Integrante Centro de Estudios e Intervenciones en Derechos Humanos Diknos.

\section{Emerson Harvey Cepeda Rodríguez}

sonemer86@gmail.com

Estudiante del Doctorado en Estudios Avanzados en Derechos Humanos de la Universidad Carlos III de Madrid (España). Abogado y Magíster en Derechos Humanos de la Universidad Pedagógica y Tecnológica de Colombia. Integrante Centro de Estudios e Intervenciones en Derechos Humanos Diknos.

\section{Walter Fernando Pérez Niño}

w.perez@uautonoma.cl

Doctorando de la Facultad de Derecho de la Universidad Autónoma de Chile. Docente de la Universidad Autónoma de Chile. Abogado y Magíster en Derechos Humanos de la Universidad Pedagógica y Tecnológica de Colombia.

\footnotetext{
1 Comentario recibido el 04.10.2015 y aceptado el 13.12.2015.
} 
La judicialización de la política internacional contra el terrorismo

Laura Zambrano Salazar, Emerson Cepeda Rodríguez y Walter Pérez Niño

Resumen: Con el propósito de responder a los ataques del 11 de septiembre de 2011 y fortalecer la seguridad, el presidente George Bush emitió la "military order" que negó el estatus de personas a sospechosos de terrorismo, a quienes se les dio la categoría de "detains" y se les recluyó de forma indefinida. En ese contexto, muchos países -incluido Polonia- prestaron ayuda a la CIA con programas de entrega y detención secreta en los que estuvieron los ciudadanos Abd al Rahim al Nashiri y Zayn al Abidin Muhammad Husayn (Abu Zubaydah), cuyos casos son analizados por la Corte Europea de Derechos Humanos en dos sentencias en las que se analizó la vulneración de sus derechos fundamentales. De esta manera, en este trabajo se estudian esas decisiones, desarrollando sus principales elementos como los hechos y contexto del caso, las normas de derecho internacional que se deben analizar, la fundamentación de la Corte para tomar la decisión y, finalmente, se expondrán algunas conclusiones.

Palabras Clave: terrorismo, detenciones secretas, tortura, Corte Europea de Derechos Humanos.

Abstract: In order to respond to the attacks of September 11, 2011 and strengthen security, President George Bush issued the "military order" which denied the status of "people suspected of terrorism", changed it to the category of "detains" and jailed them indefinitely. In this context, many countries -including Poland-helped the CIA with the establishment of rendition and secret detention programs, in which the citizens Abd al Rabim al Nashiri and Zayn alAbidin Mubammad Husayn (Abu Zubaydah) were included. Their cases were analyzed by the European Court of Human rights in two judgments in which the violation of their fundamental rights is studied. In this paper, we study those decisions, developing the main elements such as facts, the context of the case, the rules of international law and the motivations of the court to make the decision.

Key Words: Terrorism, Secret Detentions, Torture, European Court of Human Rights.

\section{Generalidades}

El inicio del siglo XXI estuvo marcado por un acontecimiento que sin duda cambiaría la historia: los ataques terroristas del 11 de septiembre a las torres gemelas. Como diría Chomsky, es la primera vez que las armas apuntaron hacia el otro lado. ${ }^{2}$ Este suceso histórico marcaría el rumbo de la nueva agenda política internacional trazada por la denominada lucha contra el terrorismo y la defensa de la "seguridad".

A partir de allí, en nombre de la "guerra justa contra el terrorismo" se ocasiona una clara ruptura frente a una triada de principios que hasta ese momento habían sido defendidos a ultranza: la exaltación del sistema democrático, la apoteosis del Estado de derecho y la glorificación de los

2 Noam Chomsky, El terror como política exterior de los Estados Unidos (Buenos Aires: Libros del Zorzal, 2005), 44. 
derechos humanos. En efecto, a partir del día siguiente de los atentados, el Gobierno de los Estados Unidos empieza a adoptar una serie de medidas que implantaban una justicia de excepción. ${ }^{3}$

Así, el Congreso de Estados Unidos emitió una resolución conjunta denominada Autorización para el Uso de la Fuerza Militar (Authorization for the Use of Military Force o "AUMF" por sus siglas en inglés) que facultó al Presidente a "utilizar toda la fuerza necesaria y apropiada contra las naciones, organizaciones o personas que se determine que planificaron, autorizaron, cometieron o apoyaron los ataques terroristas [...] con la finalidad de prevenir cualquier acto de terrorismo internacional futuro contra Estados Unidos por parte de dichas naciones, organizaciones o personas". ${ }^{4}$

Posteriormente, el 13 de noviembre de 2001, el Presidente George W. Bush firmó el Decreto Ejecutivo No. 066, conocido también como "military order", autorizando la "detención, tratamiento y juicio de ciertos no ciudadanos en la guerra contra el terrorismo". ${ }^{5}$ Las personas sometidas al decreto eran "detains" destinados a: i) ser prisioneros por un tiempo indeterminado, siendo sometidos a toda clase de torturas y tratos crueles inhumanos y degradantes; ii) ser juzgados por comisiones militares sin tener derecho a presentar recurso judicial alguno o a adelantar algún procedimiento; iii) no ser representados judicialmente ante ninguna corte de Estados Unidos o de una nación extranjera o ninguna corte internacional.

A partir de allí, la guerra contra el terrorismo ${ }^{6}$ impulsada inicialmente por los Estados Unidos, se globalizaría, bajo un proceso que se ha llamado "globalización armada", por cuanto muchos países del mundo reaccionaron casi de manera inmediata ante este nuevo contexto político y adoptaron esa misma estrategia para hacer frente a su disidencia interior, aún sin existir una definición consensuada del término terrorismo a nivel internacional. ${ }^{7}$ En otras palabras, esta política antiterrorista es un ejemplo de lo que Boaventura de Sousa Santos ha denominado un "globalismo localizado".

Es precisamente bajo ese contexto en el que muchos individuos fueron capturados por ser considerados como sospechosos de terrorismo, siendo inicialmente conducidos a prisiones secretas y luego a bases militares como la de Guantánamo, de tal forma que las Cortes Federales no tuvieran

Ignacio Ramonet, Guerras del siglo XXI (Madrid: Debolsillo, 2004), 59.

4 107th United States Congress, Public Law 107-40, 115 Stat. 224, 2001, http://www.gpo.gov/fdsys/pkg/PLAW-

107publ40/pdf/PLAW-107publ40.pdf (consulta el 20 de junio del 2016). Citado por: Comisión Intearmericana de Derechos Humanos (CIDH), Hacia el cierre de Guantánamo, 2015.

5 George W. Bush, Decreto Militar de 13 de noviembre de 2001, http://fas.org/irp/offdocs/eo/mo-111301.htm (consulta el 20 de junio del 2016). Citado por: CIDH, Hacia el cierre de Guantánamo, 2015.

6 Noam Chomsky dice que la guerra contra el terrorismo ha sido descrita en las altas esferas como la lucha contra una plaga, un cáncer esparcido por bárbaros, por "depravados enemigos de la mismísima civilización".

Para Helio Gallardo, esta guerra global contra el terrorismo no es una sensibilidad creada a partir de los sucesos del 11 de septiembre de 2001, por cuanto ha formado parte del "bagaje cultural" de las sociedades capitalistas, sosteniéndose desde la afirmación de un poder político absoluto que fue teorizado inicialmente por autores como T. Hobbes y J. Locke; poder absoluto que también recae sobre la vida y la muerte. Helio Gallardo, "Teoría crítica y derechos humanos. Una lectura Latinoamericana", Revista de Derechos Humanos y Estudios Sociales 4 (julio-diciembre): 72 y 73.

7 Ricardo Gascón, "El Contexto Internacional del último quinquenio. Los derechos humanos y la tortura”, en Privación de libertady derechos bumanos, coord. Observatorio del Sistema Penal y los Derechos Humanos de la Universidad de Barcelona. (Barcelona: Icaria, 2008), 72.

8 Santos define el concepto de globalismo localizado, como: "el impacto específico de las prácticas e imperativos transnacionales en las condiciones locales, que son así desestructuradas y reestructuradas con el fin de responder a dichos imperativos". Boaventura de Sousa Santos, La globalización del derecho (Bogotá: ILSA, 1998), 57. 
La judicialización de la política internacional contra el terrorismo

Laura Zambrano Salazar, Emerson Cepeda Rodríguez y Walter Pérez Niño

jurisdicción para conocer los recursos judiciales presentados por aquellos detenidos. ${ }^{9}$ Como si fuera poco, el Gobierno de Estados Unidos consideró que tampoco les sería aplicable el Tercer Convenio de Ginebra aplicable a los prisioneros de guerra, por cuanto éste no protegía a los miembros de la organización Al'Qaeda, por ser un actor no estatal. La situación de dichos individuos solo puede compararse con la de los judíos en los campos de concentración. Así, tanto en la base naval de Guantánamo como en la prisión de Abu Ghraib, "la nuda vida encuentra su máxima indeterminación". ${ }^{10}$

En el año 2014, el senado de los Estados Unidos presentó un informe sobre el programa de detención secreta de la CIA que reveló los métodos de tortura a los que fueron sometidos los detenidos por sospecha de terrorismo, como el denominado water-boarding (simulacros de ahogamiento), los simulacros de ejecución, las amenazas de violencia sexual y otras formas de tortura u otros tratos crueles, inhumanos o degradantes. Asimismo, quedó en evidencia la complicidad con la que actuaron países como Polonia al establecer en sus territorios, prisiones secretas donde se llevó a cabo semejante crueldad. ${ }^{11}$

\section{Contexto específico de cada caso}

\subsection{Caso Husayn (Abu Zubaydah) vs. Polonia}

El 27 de marzo de 2002 agentes de los Estados Unidos y Pakistán hallaron al señor Husayn en una casa en Faisalabad, Pakistán. En el transcurso de la operación, le dispararon varias veces en la ingle, el muslo y el estómago, lo que resultó en heridas muy graves. Posteriormente fue dejado bajo custodia de la CIA.

En el momento de su captura fue considerado uno de los miembros clave Al'Qaeda y descrito por las autoridades estadounidenses como el "tercer o cuarto hombre" en Al'Qaeda, que había tenido un

9 Una de las razones por las que una corte distrital no podría ejercer adecuadamente su jurisdicción sobre un recurso de hábeas corpus presentado a favor de un extranjero detenido en Guantánamo consistía en el l acuerdo entre EEUU y Cuba para el uso de la bahía de Guantánamo, en el que se reconoció la continuidad de la soberanía máxima de la república de Cuba respecto del territorio y las aguas sometidas a este acuerdo. En este sentido, "la bahía de Guantánamo fue considerada como una zona libre de leyes donde los agentes podían detener a no ciudadanos fuera del territorio soberano de EEUU y sin interferencia de las Cortes federales." Comisión Interamericana de Derechos Humanos (CIDH), Hacia el cierre de Guantánamo, 2015, párrafo 75.

10 Para Agamben, el significado biopolítico del estado de excepción como estructura original en la cual el derecho incluye en sí al viviente a través de su propia suspensión, emerge con claridad en aquel military order. Giorgio Agamben, Estado de excepción (Buenos Aires: Adriana Hidalgo Editora, 2010), 27.

11 Amnistía Internacional, "Informe del Senado sobre programa de detención de la CIA no debe ser el final de la historia", https://www.es.amnesty.org/noticias/noticias/articulo/informe-del-sentado-sobre-programa-de-detencion-de-la-cia-no-debe-serel-final-de-la-historia/ (consulta el 20 de junio del 2016). BBC Mundo, "Qué dice el informe sobre los interrogatorios de la CIA", http://www.bbc.com/mundo/noticias/2014/12/141209_eeuu_informe_cia_tortura_senado_tsb (consulta el 20 de junio del 2016). 
papel en todas sus operaciones terroristas, incluyendo el papel de planificador de los ataques del 11 de septiembre de 2001. De esta manera, el Señor Husayn fue considerado como el primer "detenido de alto valor" en poder de la CIA.

Posteriormente -durante más de cuatro años a partir de su captura- el solicitante estuvo bajo un régimen de incomunicación en centros secretos de detención también conocidos como "sitios negros" administrados por la CIA en todo el mundo -uno de ellos en territorio polaco-.

Al ser el primer detenido de alto valor de la CIA, en él se pusieron a prueba varios tipos de tortura, incluido el waterboarding, el confinamiento en una caja, exposición a bajas temperaturas, vendar los ojos y encapuchar dentro del centro de detención, confinamiento solitario, exposición de ruido constante, luz continua, uso de grilletes, privación de sueño y de alimentos, todo con el fin de que confesara o brindara información que le sirviera al Gobierno en su lucha contra el terrorismo.

El 22 de septiembre de 2003 fue trasladado por medio de entregas extraordinarias desde territorio polaco, a otra prisión secreta de la CIA. Se estima que dichos lugares pudieron ser: la Bahía de Guantánamo, Marruecos, Lituania y Afganistán, desde donde fue traslado nuevamente a Guantánamo.

De esta manera, desde septiembre de 2006, el solicitante ha permanecido en condiciones extremas de detención en la base Naval de Guantánamo, sin que haya sido acusado de ningún delito y tampoco está en lista para ser juzgado por una comisión militar.

\subsection{Caso Al Nashiri vs. Polonia}

A finales de octubre de 2002, el Señor Al Nashiri fue capturado en Dubai, en los Emiratos Árabes Unidos. Las autoridades estadounidenses consideran que el solicitante ha sido una de las figuras de más alto rango en $\mathrm{Al}^{\prime} \mathrm{Q}$ aeda y sospechoso de un ataque terrorista que tuvo lugar en Adén, Yemen a un barco de la marina de Estados Unidos, que mató a 17 marineros e hirió a otros 40.

En noviembre de 2002 fue transferido a la custodia de la CIA, siendo llevado a una prisión secreta de la CIA en Afganistán conocido como el "Pozo de Sal". Luego fue llevado a otro centro de detención en Bangkok, Tailandia, donde permaneció hasta el 4 de diciembre de 2002 cuando fue trasladado a Szymany base aérea militar en Polonia.

Durante su detención el solicitante fue privado de todo contacto con su familia y el mundo exterior y sometido a diversas formas de malos tratos como los que fue víctima Husayn.

El 6 de septiembre de 2006 el Presidente Bush reconoció públicamente que 14 "detenidos de alto valor" incluido el demandante, habían sido trasladados para Guantánamo. Por lo anterior, es de suponer que desde esa fecha el señor Al Nashiri ha estado detenido en aquél lugar. 


\section{Normatividad que fundamenta las decisiones}

Para la evaluación de los casos relatados, la Corte Europea de Derechos Humanos, además de los derechos del Convenio Europeo invocados como vulnerados en la demanda, también considera otras normas internacionales y fuentes públicas. Así, a continuación se expondrá el marco normativo tenido por la Corte para analizar los asuntos.

\subsection{Normas del Convenio Europeo de Derechos Humanos}

En primer lugar encontramos los artículos 1, 2, 3, 5, 6, 8 y 13 del Convenio denunciados como vulnerados por la parte actora ${ }^{12}$, los cuales se desarrollan de la siguiente manera:

El artículo 1 estipula el compromiso de las partes de reconocer los derechos y libertades del Convenio a todas las personas bajo su jurisdicción.

El artículo 2 protege el derecho a la vida, salvo condena debidamente impuesta por un tribunal para delitos que contemplen la pena de muerte.

El artículo 3 de señala que nadie podrá ser sometido a tortura ni a penas o tratos inhumanos o degradantes.

El artículo 5 ampara el derecho a la libertad y seguridad, para ello sostiene que la privación de la libertad solo es posible, entre otros, para siguientes casos: a) cuando exista sentencia dictada por un juez competente; b) conforme a derecho por desobediencia de una orden judicial o para asegurar el cumplimiento de una obligación legal; c) conforme a derecho cuando existan indicios racionales de que se ha cometido una infracción, la persona huya después de haberla cometido o antes para prevenirla; d) conforme a derecho para impedir una entrada ilegal al territorio o cuando se esté en curso un proceso de expulsión o extradición. De igual manera establece el deber de las autoridades respectivas de: informar a las personas privadas de la libertad, en una lengua comprensible para ellas, los motivos de la detención y de acusación en su contra; conducir a los detenidos sin dilación a los jueces o autoridades competentes; juzgar en plazos razonables y; permitir la interposición de recursos para la revisión de la legalidad de la detención. Finalmente, resalta el derecho que tienen las personas arrestadas de ser reparadas en caso de que su captura se hubiese realizado contradiciendo la ley.

El artículo 6 hace referencia al debido proceso y el correspondiente el deber de los Estados partes de garantizar a las personas: a) ser oído en juicio de manera pública y en un plazo razonable por un tribunal imparcial establecido en la ley, aunque es posible la restricción del acceso a la sala de

12 Los derechos invocados en los casos son idénticos a excepción de los artículos 1 y 2 que no se menciona en la sentencia Husayn vs. Polonia. 
audiencias para la protección de la vida privada, el orden público, intereses de los menores o la seguridad nacional; b) la presunción de inocencia hasta que la persona no haya sido declarada culpable; c) el derecho a defenderse, interrogar y contrainterrogar a testigos, y tener defensa técnica, proporcionando, de ser necesario, un abogado de oficio y; d) tener un intérprete en caso de que la persona no comprenda el idioma utilizado en la audiencia.

El artículo 8 hace referencia a la obligación de los Estados de respetar la vida privada y familiar de las personas, que solo puede ser restringida en los casos previstos en la ley, siempre y cuando estén fundados en razones de seguridad nacional, bienestar económico del país, prevención de infracciones penales, o para la protección de la salud, la moral o los derechos y libertades de los demás.

El artículo 13 salvaguarda el derecho de toda persona a contar con un recurso efectivo, ante una instancia nacional, cuando crea vulneradas las garantías reconocidas en el Convenio.

Además de los artículos indicados, teniendo en cuenta las actuaciones procesales realizadas por el Estado demandado, la Corte revisa el cumplimiento del artículo 38, que trata del compromiso de los Estados de dar todas las facilidades en los requerimientos realizados por el Tribunal.

\subsection{Derecho internacional}

Para el estudio de los casos, en la jurisprudencia reseñada la Corte se expone las siguientes normas de derecho internacional:

Los artículos 26 y 27 de la Convención de Viena Sobre el Derecho de los Tratados, normas que consagran las obligaciones de las partes de: respetar de buena fe los convenios una vez firmados y no invocar como excusa disposiciones de derecho interno.

También se hace alusión a la ILC (International Law Comission por sus siglas en inglés), especialmente a los artículos 7, 14, 15 y 16 de sus normas aprobadas en 2001, en donde se considera un acto de Estado aquel realizado por una persona o entidad facultada para ejercer el poder, incluso si excede esa capacidad.

El artículo 7 del Pacto internacional de Derechos Civiles y Políticos que prohíbe las torturas y tratos crueles e inhumanos.

La Convención Contra la Tortura de las Naciones Unidas, que en su artículo primero, define dicho comportamiento como un acto en el que intencionalmente se infringe dolor o sufrimientos graves ya sean físicos o mentales, con el propósito de obtener información, confesión, o como forma de castigo, intimidación o coacción. De la misma forma prohíbe la expulsión o extradición de una persona si hay razones para creer que será sometida a tortura. 
La judicialización de la política internacional contra el terrorismo

Laura Zambrano Salazar, Emerson Cepeda Rodríguez y Walter Pérez Niño

La Resolución 60/147 de la Asamblea General de la ONU en la que se reitera el derecho de las víctimas de violaciones de derechos humanos de obtener reparaciones y a obtener información sobre las causas de su victimización.

\subsection{Fuentes públicas}

El Tribunal considera también los informes de Organizaciones Internacionales.

En primer lugar, revisa la declaración de la Alta Comisionada de Derechos Humanos de los Talibanes y Militantes de Al'Qaeda detenidos en Guantánamo de las Naciones Unidas, la Declaración de Consejo Internacional de Rehabilitación de la Tortura y la Opinión 29/2006 del Grupo de Trabajo de Sobre la Detención Arbitraria, en los que se resalta la preocupación por las condiciones de los presos en Guantánamo y de las demás personas retenidas en centros de detención de Estados Unidos en varios países.

Tuvo en cuenta los informes de Amnistía Internacional en los que expresa su intranquilidad por las acciones del gobierno de Estados Unidos de transferir y mantener a personas en condiciones que se podrían calificar como crueles, inhumanas o degradantes, denegándoles sus derechos a la defensa y a acudir a tribunales.

Asimismo, hace alusión a la Resolución 1340 de 2003 de la Asamblea Parlamentaria del Consejo de Europa sobre los detenidos bajo custodia de los Estados Unidos en Afganistán o Guantánamo, donde también se plasma la preocupación por las condiciones de los detenidos, subrayado además que a estos no se les reconoce como prisioneros de guerra sino como "combatientes ilegales", figura que no se encuentra contemplada en el Derecho Internacional. 


\section{Argumentos de las partes}

\subsection{E1 gobierno}

En primer lugar, sobre la excepción previa de no agotamiento de recursos internos que propuso, indica que la investigación criminal sobre los hechos denunciados se encontraba pendiente y que en los procesos de la jurisdicción interna se han salvaguardado todas las garantías procesales.

En relación con el artículo 38, que establece el deber de los Estados de cooperar en los procesos adelantados en Tribunal de Estrasburgo, sostiene que no atendió a las pruebas solicitadas debido a que la información, por una parte era reserva del proceso, y por otra también era documentación secreta sobre la cual el Tribunal no ofreció garantías de confidencialidad.

Agregó que no podrían manifestarse en relación con la violación de los demás artículos invocados ya que la investigación penal seguía pendiente, de tal forma que no estaban en capacidad de afirmar o negar los hechos puestos en conocimiento.

\subsection{Solicitante}

Sobre la excepción previa de no agotamiento de recursos internos señala que las investigaciones del orden interno llevaban más de 5 años, lo que repercutió en el derecho de la parte actora a tener un recurso efectivo. En ese sentido argumenta que, como quiera que los medios procesales han sido ineficaces, no es necesario su agotamiento.

En cuanto a la vulneración del artículo 38, manifiesta que el gobierno no atendió correctamente a los requerimientos del juzgador, perjudicando el examen realizado por la Corte y obstruyendo deliberadamente la verdad.

Frente los hechos denunciados indica que estos se basan en documentación dispuesta al público, entre ellos informes e información desclasificada de la CIA donde consta la retención en Polonia de los accionantes y, los malos tratos a los que se les habría sometidos.

\subsection{Amnistía internacional y Comisión Internacional de Juristas}

En sus intervenciones ante la Corte advierten sobre el riesgo en el que se encontraban los sospechosos de terrorismo internacional por fuera de Estados Unidos de ser detenidos arbitrariamente y transferidos de forma secreta como consecuencia de la política anti terrorista. 


\section{Razonamiento jurídico de la Corte Europea de Derechos Humanos (ECHR)}

Las respuestas de la ECHR a los hechos denunciados hacen parte de los lineamientos que ha definido para el reforzamiento de los derechos humanos, en el contexto de la lucha contra el terrorismo. En particular, la intervención no solo ha sido motivada por las detenciones secretas y las extradiciones extrajudiciales lideradas por Estados Unidos y permitidas por estados europeos, ya que también se han analizado: a) la expedición de normas sobre terrorismo, seguridad nacional o ampliación de los poderes del ejecutivo, que impiden la garantía del debido proceso y el acceso a la justicia; b) la existencia de prácticas de tortura y otros tratos inhumanos, crueles o degradantes; c) la aplicación de la pena de muerte; d) la calificación de personas y grupos como terroristas o asociadas al terrorismo; y d) la detención preventiva indefinida, aplicada en Países como Francia. ${ }^{13}$

Conforme a lo mencionado, a continuación se sistematiza la práctica judicial que ha permitido definir una dogmática frente a los límites de las acciones que se realizan en contra del terrorismo (ver mapa conceptual): ${ }^{14}$

13 Organización de las Naciones Unidas, Informe del Relator Especial sobre la Promoción y la Protección de los Derechos Humanos y las Libertades Fundamentales en la Lucha contra el Terrorismo, 2008.

14 European Court of Human Rights (ECHR), Terrorism and the European Convention on Human Rights, 2015. 
Revista Tribuna Internacional

Volumen $5 \cdot \mathrm{N}^{\circ}$ 9 • 2016 • pp. 123-138

ISSN 0719-482X (versión en línea)

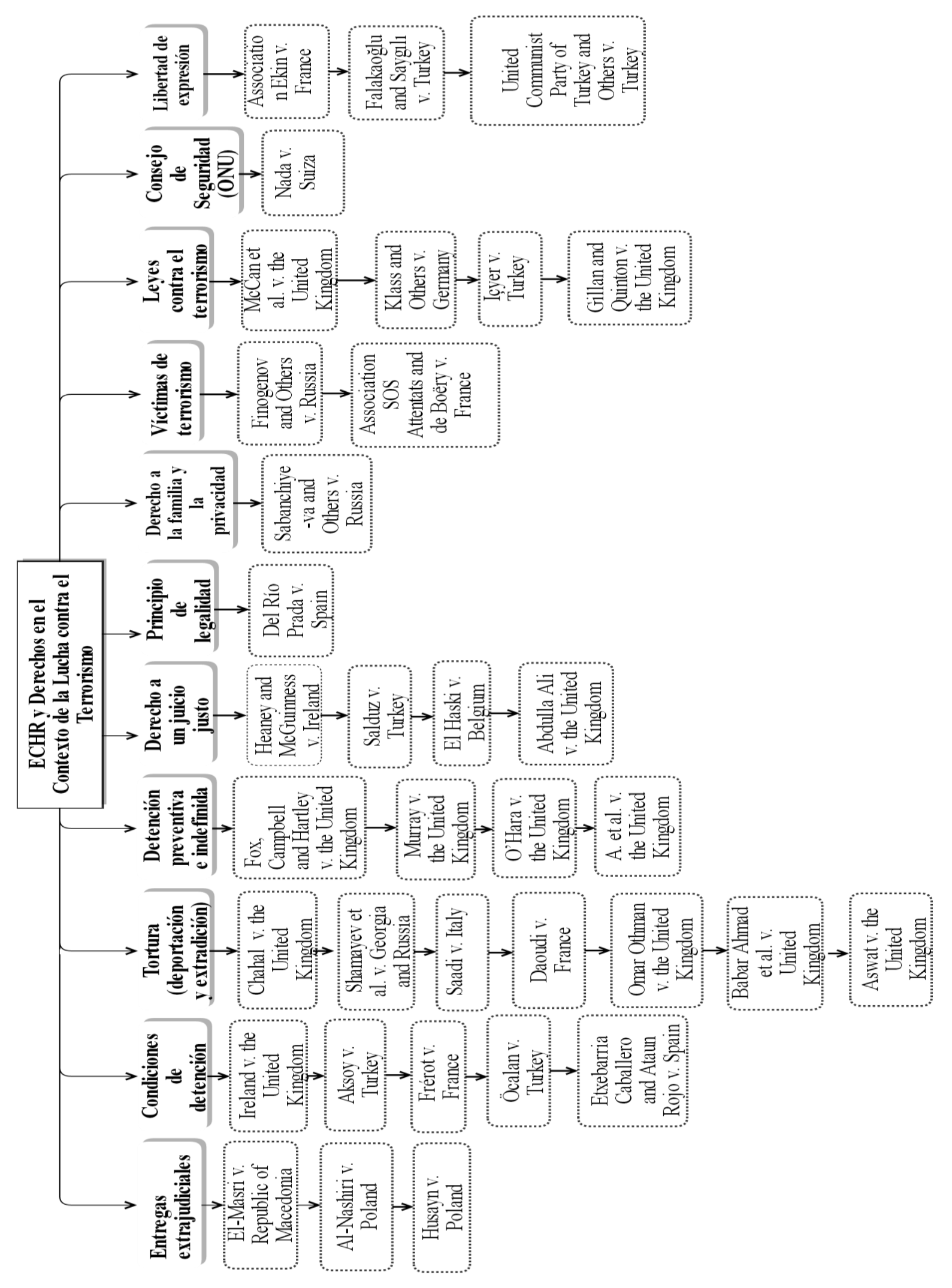


Particularmente, la ECHR al resolver los casos objeto de estudio reitera la posición que inicialmente plantea en el año 2012 en la sentencia "El Masri v. The Former Yugoslav Republic of Macedonia”, al conocer las acciones llevadas a cabo por la CIA que implicaron el arresto ilegal del ciudadano alemán Khaled El-Masri, quién es incomunicado, sometido a torturas y trasladado del aeropuerto de la República de Macedonia a una prisión en Bagdad (Afganistán).

La ECHR sostuvo la tesis, que a pesar de las grandes dificultades presentes en la investigación del delito de terrorismo, no se justifica que las autoridades tengan "carta blanca" para arrestar y detener a sospechosos sin que se cumplan los parámetros del control judicial y la Convención Europea de Derechos Humanos. ${ }^{15}$

El alcance que se fija a dicha prohibición, adquiere firmeza en las sentencias Al Nashiri y Husayn, plasmándose en una posición con alto valor simbólico en la medida que construyen un lenguaje e imaginario social respecto a la prohibición de estas acciones ${ }^{16}$, pero que en nuestra opinión pierde eficacia, ya que la reparación no fija herramientas precisas que permitan la investigación de los responsables, el conocimiento de la verdad y la garantías de no repetición. No sobra mencionar, que existen dos demandas pendientes de estos mismos ciudadanos contra los Estados de Lituania y Rumania, por los mismos hechos ${ }^{17}$; asimismo, cabe mencionar una acción dirigida contra Italia por los ciudadanos egipcios Nasr y Ghali por la participación de las autoridades italianas en la detención y el maltrato recibido. ${ }^{18}$

Desde la primera postura (5.1), la Corte determina la responsabilidad de Polonia con base en: a) la aquiescencia de los actos realizados por funcionarios norteamericanos en su territorio en el marco del programa HVD (High Value Detainee) y la previsibilidad que de la entrega extrajudicial, los demandantes se enfrentarían a un riesgo real de violación de sus derechos; b) la vulneración de la libertad; c) las prácticas de tortura llevadas a cabo en la detención secreta y el interrogatorio operado por la CIA; y d) la necesidad de realizar investigaciones judiciales efectivas.

Desde el otro punto de vista (5.2.), si bien la ECHR establece el derecho a la verdad de la víctima y la sociedad en los casos de graves violaciones de los derechos humanos, desconoce las solicitudes de reparación realizadas por los demandantes ${ }^{19}$, respecto a la obligaciones de reconocer la responsabilidad estatal, abrir una investigación efectiva que identifique y sancione a los responsables y finalmente, publicar los hechos probados.

15 European Court of Human Rights (ECHR), El Masri v. The Former Yugoslav Republic of Macedonia, 2012, para. 232.

16 César Rodríguez y Diana Rodríguez, Cortes y cambio social. Cómo la Corte Constitucional transformó el desplazamiento forzado en Colombia, (Bogotá: Dejusticia, 2010), 289.

17 European Court of Human Rights (ECHR), Al Nashiri v. Romania, 2012. EHCR, Abu Zubaydah v. Lithuania, 2011.

18 European Court of Human Rights (ECHR), Nasr and Ghali v. Italy, 2011.

19 European Court of Human Rights (ECHR), Husayn (Abu Zubaydah) v. Poland, 2014, para. 563. 


\subsection{La fundamentación de los derechos}

En primer lugar, la Corte determina que Polonia es responsable al facilitar y crear las condiciones para que se desarrollaran las actividades de la CIA, más aún, cuando tenía conocimiento de la naturaleza y fines de estas, particularmente, de la extradición extrajudicial, las condiciones de detención en sitios secretos ubicados en su territorio y el riesgo previsible que las personas privadas de la libertad enfrentarían tortura y otros tratos inhumanos crueles y degradantes.

En consecuencia, la ECHR menciona que estos hechos son totalmente contrarios a la Convención Europea de Derechos Humanos (la Convención), específicamente al artículo 1, que señala la obligación positiva de los estados de tomar medidas que garanticen que los individuos dentro de su jurisdicción no sufran un menoscabo de sus derechos, incluidas aquellas estrategias que impidan que estas violaciones provengan de particulares o la cooperación con agentes del gobierno.

De otro lado, al referirse a la decisión del Estado de participar y permitir el programa de extradiciones extrajudiciales de una jurisdicción a otra, estableció que desconoció los artículos 2 (derecho a la vida), 3 (prohibición de la tortura), 5 (libertad y seguridad) de la Convención, así como los artículos 1 y 2 (prohibición de la pena de muerte) de su Protocolo adicional 6, que prohíben la extradición o deportación de una persona cuando se conoce con seguridad que los demandantes tenían un riesgo real de ser sometidos a la pena de muerte, sobre todo cuando se había eludido el debido proceso.

En segundo lugar, la EHCR comprueba que la realización del programa HVD, específicamente con la detención arbitraria, necesitaba de la cooperación y de distintas formas de asistencia de autoridades de otros países, debido a que la finalidad perseguida por Estados Unidos y los estados cooperantes, era sustraer a las personas de cualquier garantía legal de la Constitución de los Estados Unidos y el derecho internacional.

En particular, la Corte sostiene que existió una vulneración del derecho a la libertad y la seguridad (artículo 5, Convención), ya que con la privación injusta se infringió el corpus de derechos sustantivos establecidos para minimizar el riesgo de arbitrariedad, dentro de los que cabe señalar el control judicial independiente e intervención judicial dentro de un plazo razonable. De esta manera, la Corte determina que el valor que tiene la lucha contra el terrorismo no es superior a la supervisión judicial que debe operar por tribunales nacionales y la Convención.

En un tercer escenario, el Tribunal encontró que los detenidos fueron sistemática y continuamente sometidos a medidas agresivas (golpes, amenazas, confinamiento en espacios pequeños (cajas), exposición a bajas temperaturas, privación de alimentos, entre otras). Frente a estos hechos concretos, la ECHR consideró que este tratamiento ascendió a tortura, delito que había sido permitido por Polonia, al facilitar los medios para realizar éstas prácticas y no impedir la lesión de la integridad de las víctimas, sobre todo cuando de la interpretación conjunta del artículo 1 (obligación 
La judicialización de la política internacional contra el terrorismo

Laura Zambrano Salazar, Emerson Cepeda Rodríguez y Walter Pérez Niño

de respetar los derechos humanos) y 3 (prohibición de la tortura), no solo se desprenden obligaciones negativas de abstención, sino medidas de prevención o positivas que garanticen que las personas no sean sometidos a torturas por particulares o funcionarios extranjeros.

Igualmente, las sentencias relacionan las reglas en garantías judiciales y protección judicial en dos escenarios fácticos: a) la violación al debido proceso de las víctimas al ser sometidos a la investigación y juzgamiento por comisiones militares y b) la inexistencia de pruebas que confirmaran que Polonia hubiese desarrollado investigaciones eficaces o presentado cargos penales en contra de las personas involucradas en el programa HVD, a pesar que ya habían pasado más de 10 años desde la fecha en la que este Estado fuera nombrado públicamente como un país que albergaba una prisión secreta.

Frente al primer contexto, la Corte decide decretar la violación del artículo 6 no. 1 (Debido Proceso) de la Convención, al sostener que un civil al comparecer ante un tribunal compuesto total o parcialmente por militares, las garantías de imparcialidad están sometidas a una duda razonable, que equivale a la violación integral del derecho a un juicio justo. Teniendo en cuenta lo mencionado, determinó que la comisión militar no ofrecía la protección suficiente a este derecho, ya que no tenía legitimidad en consonancia con la ley norteamericana y el derecho internacional, y las pruebas las obtenían bajo prácticas de tortura.

Para resolver la falta de investigación y sanción a los responsables, reconoció que debe existir una investigación judicial rápida, exhaustiva e independiente, que permita la identificación y sanción plena, la participación de las víctimas y el pago de una indemnización justa.

\subsection{Temas pendientes en las decisiones de la Corte Europea de Derechos Humanos}

Los anteriores argumentos, si bien describen los límites que no deben sobrepasar los estados en la lucha contra el terrorismo, la ECHR muestra cierta indecisión al asegurar que la dogmática expuesta se refleje en los contenidos de la reparación.

En este sentido, una de las primeras omisiones se originan cuando la Corte, a pesar de que menciona que la confidencialidad de la investigación por razones de seguridad nacional no debe sacrificar la divulgación a la víctima o el público, ya que vulnera el derecho a la verdad de la víctima y la sociedad en general, el reconocimiento no lleva a que la ECHR ordene al Estado de Polonia desplegar todos los medios para continuar con las investigaciones, con el fin de individualizar, juzgar y sancionar a todos los responsables.

También se desconoce la resolución de la Asamblea General de las Naciones Unidas "Principios y directrices básicos sobre el derecho de las víctimas de violaciones manifiestas de las normas internacionales de derechos humanos y de violaciones graves del derecho internacional humanitario a interponer recursos y obtener reparaciones", que establece que en el momento de realizar la reparación se deben considerar distintas medidas con 
el fin de resarcir los daños de forma integral, adicionales a la compensación monetaria establecida dentro de la sentencia, como la restitución, la satisfacción y las garantías de no repetición. ${ }^{20}$

\section{Conclusiones}

La guerra contra el terrorismo impulsada por los Estados Unidos se globalizó. Producto de ello, varios países del mundo se convirtieron en cómplices de la CIA al tener en sus territorios prisiones secretas a las cuales, trasladaban inicialmente a quienes detenían como sospechosos de terroristas, los sometían a diferentes clases de "técnicas de interrogación mejoradas" con el fin de obtener una confesión o información relacionada con el terrorismo. Luego de ello, los “detains" eran trasladados a bases militares como "Guantánamo".

Bajo este contexto, Husayn y Al Nashiri fueron detenidos como sospechosos de pertenecer a Al'Qaeda y de ser partícipes de atentados terroristas, fueron conducidos a prisiones secretas establecidas en territorio de Polonia y sometidos a tortura, así como a tratos crueles, inhumanos y degradantes. Los dos siguen privados de su libertad en Guantánamo.

Probatoriamente la sentencia posee aspectos interesantes. En primer lugar, resalta el deber de colaboración de los Estados conforme el artículo 38 del Convenio, para que de esa manera se pueda llevar a cabo la recaudación probatoria necesaria con el fin de esclarecer los hechos relatados por los accionantes, dejando claro que ni el carácter reservado de una documentación puede ser excusa para no acatar las órdenes dadas por el Tribunal. En segundo lugar, y ante la falta de colaboración por parte del Estado Polaco, destaca que la Corte para llegar a la verdad puede utilizar diferentes medios probatorios para superar este obstáculo.

La intervención que realiza la Corte Europea es provechosa en la medida que permite definir límites claros que no se deben sobrepasar por los estados en los programas y acciones desplegadas contra el terrorismo, no sólo en los escenarios fácticos propuestos por la sentencia, ya que como se presentó en este trabajo, se han definido otros criterios consistentes para proteger los derechos humanos. También es indudable que las decisiones proferidas, así como el primer caso de El-Masri, son pasos iniciales que se dan frente a una violación difícil de abordar, debido a que Estados Unidos es el promotor de la política de entregas extrajudiciales, no obstante, los argumentos expuestos permiten reforzar la competencia de la Corte al conocer este tipo de hechos, establecer obligaciones positivas para que los estados europeos prevengan estos hechos y fortalecer una cultura en derechos humanos.

Por último, se reduce la posibilidad de restablecer los derechos vulnerados y por los cuales fue sancionado Polonia, particularmente, cuando no existe correspondencia entre los criterios

20 Resolución A/RES/60/147 de la Asamblea General de las Naciones Unidas, 21 de marzo de 2006, párrafo 11-24. 
La judicialización de la política internacional contra el terrorismo

Laura Zambrano Salazar, Emerson Cepeda Rodríguez y Walter Pérez Niño

dogmáticos con los mecanismos de reparación ordenados, más aún, cuando no se resuelven integralmente las solicitudes de las víctimas.

Por tanto, una perspectiva que pudo integrar y visibilizar estos lineamientos consistiría en: 1) continuar con las investigaciones, para individualizar, juzgar y sancionar a los responsables; 2) realizar un acto público de reconocimiento de responsabilidad; 3) garantizar los derechos y la seguridad de las personas que se encuentren en su territorio, particularmente, prohibir de forma expresa la instalación o permanencia de cárceles secretas o todos aquellos actos relacionados con la facilitación de actividades de la CIA; y 4) asegurar la publicación de los hechos probados en la sentencia, para el conocimiento de la sociedad. 